\title{
PRZYCZYNEK DO BADAŃ NAD STYLEM URADZKIM W ZACHODNIEJ WIELKOPOLSCE NA PRZYKLADZIE MATERIALÓW Z CMENTARZYSKA WE WARTOSŁAWIU, POW. SZAMOTULSKI
}

\author{
CONTRIBUTION TO THE RESEARCH ON THE URAD \\ STYLE IN THE WESTERN GREATER POLAND, BASED ON THE \\ EXAMPLE OF MATERIALS FROM THE CEMETERY \\ IN WARTOSŁAW, SZAMOTULSKI DISTRICT
}

\author{
Jagoda Mizerka \\ https://orcid.org/0000-0001-9172-8264 \\ Ośrodek Studiów Pradziejowych i Średniowiecznych \\ Instytut Archeologii i Etnologii PAN \\ ul. Rubież 46, 61-612 Poznań \\ jagodamiz@o2.pl
}

\begin{abstract}
This article presents the issues of the Urad style on the example of ceramics and metal products from the cemetery in Wartosław. The ceramic was obtained in the 19th century as a result of amateur research and in 2009 during archaeological excavations. Findings concerning the definition of the style of Uradzka ceramics and the interpretation possibilities of this phenomenon, registered in western Greater Poland, in the Lubusz region and in eastern Brandenburg, are presented.
\end{abstract}

KEY WORDS: Lusatian urnfields, Urad style, cemetery, late Bronze Age

Badania nad stylistyką uradzką, stanowiącą jeden z wyróżnionych stylów w ceramice ludności łużyckich pól popielnicowych, sięgają końca XIX w. Od tamtej pory źródła te identyfikowane są dość często w zespołach pochodzących z badań z zachodniej Wielkopolski oraz na terenie Ziemi Lubuskiej i Brandenburgii. Stylistyka ceramiki naczyniowej, jak i zasięg terytorialny grupy uradzkiej zostały zdefiniowane i są używane w literaturze przedmiotu od 1880 roku (Virchow, 1880; Voss, 1887). Taki wydawałoby się usystematyzowany i mocno ugruntowany w literaturze przedmiotu 
obraz stylu uradzkiego może dawać błędne przeświadczenie o rozpoznaniu i zrozumieniu tego zjawiska. Truizmem będzie stwierdzenie, że nowych danych dostarczać mogą pogłębione studia nad materiałami pozyskanymi z cmentarzysk i osad ludności łużyckich pól popielnicowych. Rozważania te nie muszą opierać się tylko na bieżąco pozyskiwanych materiałach, ale również na starszych, pochodzących z badań z XX w., które mogą zostać poddane ponownej interpretacji. W niniejszym artykule przeanalizowane zostały materiały pochodzące z nekropoli w Wartosławiu, pozyskane w końcu XIX w. oraz w 2009 roku¹, które można łączyć z IV EB. Stanowić one mogą tło do rozważań nad stylistyką uradzką i jej pozycją w ramach tzw. „kultury łużyckiej”, ze szczególnym uwzględnieniem wpływu, jaki wywierały na stylistykę naczyń występujących na terenach sąsiadujących.

\section{HISTORIA BADAŃ STYLU URADZKIEGO}

Niemal równocześnie z wprowadzeniem do obiegu terminu „typ łużycki” (Virchow, 1880, s. 228), materiały archeologiczne pozyskane z eponimicznego cmentarzyska w Uradzie ${ }^{2}$ stały się podstawą do stworzenia i wprowadzenia do obiegu pojęcia stylu uradzkiego (Voss, Stimming, 1887). Pierwszej próby scharakteryzowania tego zjawiska podjął się A. Götze w 1897 roku (1897, s. 30-32). Ów szkic został poszerzony kilka lat później przez A. Voßa (1903, s. 179-184) oraz ponownie przez A. Götzego (1924), który określił także zasięg wydzielonej przez siebie grupy uradzkiej. Na terenach położonych na zachód od Odry źródła te analizował J. Schneider (1958, s. 5-70). W literaturze polskiej zaczęto używać bezkrytycznie terminu ,grupa uradzka" jako tożsamą z ,grupą zachodniowielkopolską" i chronologicznie obejmującą całą ceramikę młodszo- i późnobrązową (IV-V EB) (Kostrzewski 1955, s. 103; Kostrzewski, Chmielewski, Jażdżewski, 1965, s. 158). Miała ona wypełniać lukę między charakterystyczną ceramiką guzową, rozwijającą się w początkach funkcjonowania ludności łużyckich pól popielnicowych a ceramiką halsztacką, wieńczącą rozwój opisywanej jednostki kulturowej (Kaczmarek, 2008, s. 19). Znacznie ograniczył i redefiniował pojęcie stylu uradzkiego M. Gedl (1975, s. 118-119), który w zaproponowanym terminie umieścił ceramikę charakteryzującą się ostrą profilacją, pojawiającą się we wschodniej Brandenburgii, na ziemi lubuskiej i w zachodniej Wielkopolsce w IV EB. Takie ujęcie zostało wprowadzone i obecnie funkcjonuje w polskiej literaturze przedmiotu (Marcinkian, 1986, s. 110; 2010; Bukowski, 1998, s. 21; Kaczmarek, 2002, s. 69-71).

\footnotetext{
${ }^{1}$ Analiza obrządku pogrzebowego, jaki zaobserwowano w badanej strefie cmentarzyska, a także pełne katalogi zawierające opis obiektów grobowych i ich inwentarzy zostały przedstawione w opracowaniu stanowiska. Por. Mizerka, Krzyszowski, 2019; Mizerka, 2019.

2 Obecnie wieś Urad w województwie lubuskim, w powiecie słubickim.
} 
Pod pojęciem ceramiki uradzkiej rozumiany jest zespół informacji dotyczących jej morfologii oraz zdobnictwa, z których najistotniejszą i najbardziej wyróżniającą cechą jest ostra profilacja, wynikająca ze znacznego uproszczenia tektoniki naczyń oraz kształtowanie silnych załomów (Kaczmarek, 2002, s. 69). Charakterystyczne dwustożkowate brzuśce posiadają naczynia o dużych rozmiarach, takie jak wazy, amfory, dzbany oraz ich zminiaturyzowane formy. Opisywany styl identyfikują stożkowate kubki z charakterystycznym kołnierzowato wychylonym wylewem, nazywane naczyniami moździerzowatymi, a także wysokie kubki cylindryczne. Charakterystyczne dla tego stylu są także tzw. naczynia cylindryczne, czyli proste kubki z dwoma symetrycznie rozmieszczonymi małymi i poziomo przekłutymi uszkami oraz stożkowate formy mis. Niewątpliwie jednak do jednego z najbardziej dystynktywnych typów naczyń zaliczyć można tzw. puchary uradzkie. Są to dwustożkowate wazy osadzone na wysokich, pustych nóżkach. Cechą odznaczającą naczynia są rożkowate bądź facetowane ucha doklejane do powierzchni kubków czy czerpaków. Ostatnią charakterystyczną grupę stanowią kubki oraz dzbany z kulistymi dnami. Pozostałe naczynia, występujące $\mathrm{w}$ zespołach $\mathrm{z}$ tego okresu, nie mają wyróżniających cech, stanowiąc uniwersalne, długotrwałe formy występujące od III EB po okres halsztacki. Wśród nich są zarówno jajowate garnki, proste kubki, a także miseczki i czerpaki w kształcie wycinka kuli oraz proste, szerokootworowe misy.

Ornamentyka naczyń uradzkich jest ograniczona do prostych, nieskomplikowanych wątków. Zasadniczo opierają się one na elementach rytych oraz odciskanych, rzadziej zaś plastycznych. Tworzą je w znacznej mierze występujące pojedynczo lub w kompilacjach: dookolne linie ryte, małe dołki oraz ukośne nacięcia. Należy podkreślić, że część naczyń pozbawiona jest całkowicie zdobienia lub ograniczona do występowania np. pojedynczego dołka. Wewnętrzne i zewnętrzne partie den mis pokrywa czasem motyw równoramiennego krzyża, zaś ich wylewy ukośne kanelury. Podobne, aczkolwiek poziomo ułożone kanelury znajdują się na nóżkach pucharów uradzkich. Do bardziej rozbudowanych i charakterystycznych sposobów zdobienia naczyń należy tzw. szczątkowy ornament guzowy. Występuje na największej wydętości brzuśców waz, amfor oraz dzbanów i stanowi nawiązanie do poprzedniego etapu rozwojowego, czyli stylu guzowego. Na wspomniany ornament składają się małe, nalepiane guzy, które otaczają pojedyncze bądź zwielokrotnione półkoliste kanelury lub żeberka. Równie rozpoznawalnym wątkiem zdobniczym stylistyki uradzkiej jest motyw jodełki.

\section{ŹRÓDŁA Z WARTOSŁAWIA}

Przedstawiona powyżej krótka charakterystyka pozwoli przyjrzeć się źródłom ze stanowiska będącego pretekstem do napisania niniejszego tekstu. Cmentarzysko ludności łużyckich pól popielnicowych w Wartosławiu (ryc. 1), znane również pod nazwą Wartosław-Biezdrowo-Zakrzewo, położone jest w północno-zachodniej części Wielkopolski (Malinowski, 1961; Krzyszowski, 2019, s. 13-14). Pierwsze 


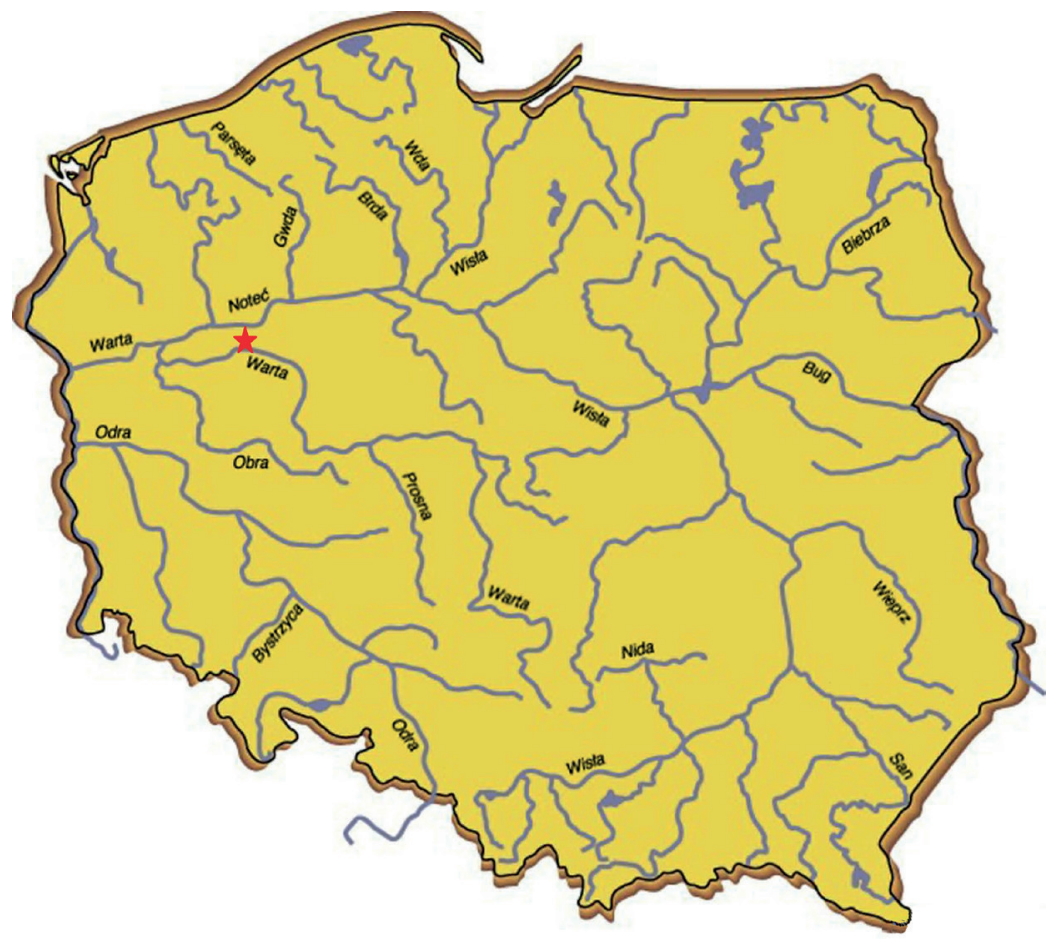

Ryc. 1. Wartosław stan. 1, pow. szamotulski. Lokalizacja ciałopalnego cmentarzyska ludności łużyckich pól popielnicowych (oprac. J. Mizerka)

Fig. 1. Wartosław site 1, Szamotulski district. Location of the cremation cemetery of the Lusatian population of Urnfield culture (fig. prep. J. Mizerka)

amatorskie rozkopywanie grobów miało na nim miejsce w końcu XIX w., natomiast metodyczne badania wykopaliskowe odbyły się w latach 60. XX w. oraz w 2009 roku (Łopata, 1964, s. 12-76; Mizerka, 2016; Mizerka, 2019, s. 45-71; Krzyszowski 2019, s. 73-85). W zbiorze, który obejmował źródła XIX-wieczne oraz te pochodzące z 2009 roku, znajdowało się 274 form naczyń, których cechy morfologiczne pozwoliły powiązać je ze stylistyką uradzką (Götze, 1897, s. 30-32; Götze, 1924; Kaczmarek, 2002, s. 67-72; Kaczmarek, 2005, s. 136-139). Znalazły się wśród nich ostroprofilowane wazy $\left(32^{3}\right)$ (ryc. 2: 2-5), amfory (21) (ryc. 3: 1-4) oraz dzbany (5). Pojawiły się także egzemplarze dzbanów $\mathrm{i}$ ich miniatur z kulistym dnem z charakterystycznymi facetowanymi uchami (36) (ryc. 2: 6). Wśród kubków zidentyfikowano te z baniastymi brzuścami oraz kulistymi dnami (13), wysokie i proste egzemplarze (7) (ryc. 4: 1, 2, 4, 5), a także moździerzowate (22) (ryc. 4:3) oraz dużą grupę naczyń cylindrycznych (61) (ryc. 5: 3,4). Wśród wyróżniających się typów garnków były te z wychylonym

\footnotetext{
${ }^{3}$ W nawiasach podano liczbę znalezionych egzemplarzy naczyń.
} 
na zewnątrz wylewem (14), garnki tulipanowate (7) (ryc. 3: 5, 6) oraz typ z pogrubioną i kołnierzowato wychyloną krawędzią (1). Za jedne z najbardziej diagnostycznych naczyń w zespole należy uznać puchary (8) (ryc. 6: 1-5) oraz charakterystyczne szerokie nóżki pochodzące ze zniszczonych egzemplarzy (15). W zespole znalazły się również formy specjalne (3), które charakteryzowały się baniastymi brzuścami z bardzo wysokimi, cylindrycznymi szyjkami (ryc. 7: 1-3). Stylistyka uradzka widoczna była także w ukształtowaniu uch, dolepianych często do niedystynktywnych odmian naczyń. Formy rożkowate zanotowano na donicowatych kubkach (5) (ryc. 5: 1,2 ) oraz czerpakach o niewyodrębnionych dnach (2) (ryc. 5: 5, 6), natomiast facetowane ucha $\mathrm{z}$ charakterystycznym daszkiem miały donicowate kubki (6) i czerpaki (4). Ceramika wartosławska przejawiała standardowe dla stylistyki uradzkiej zdobienia. Składały się na nie wątki ryte w postaci dookolnych linii (ryc. 2: 2; 4: 2, 4, 5), występujących w połączeniu z dołkami, nakłuciami (ryc. 2: 3, 4; 4:3) lub proste, ryte elementy (ryc. 5: 3,4). Wszystkie egzemplarze amfor, a także niektóre z dzbanów łączyło posiadanie ornamentyki, której elementem były guzy występujące samodzielnie lub otaczane półkolistymi kanelurami (ryc. 3: 1, 2, 3), względnie żeberkami (ryc. 3: 4). Typowy dla opisywanej stylistyki motyw jodełki posiadała waza, wzbogacona także o nacięcia i dołki (ryc. 2: 5), dwa naczynia cylindryczne oraz jeden z pucharów (ryc. 6: 5). Ornament plastyczny ograniczał się do występowania podkrawędnych guzów oraz listwy z dołkami palcowymi (ryc. 3: 5).

Zaledwie trzy przedmioty brązowe można przypisać do tej grupy chronologicznej. Wśród nich znajdował się bogato zdobiony tutulus z kolcem wychodzącym z górnej tarczki i grzybkowatą główką (ryc. 8: 1) wg E. Sprockhoffa (1937, s. 53). Ozdoby tego typu są charakterystyczne dla południowej strefy kultury nordyjskiej (Kaczmarek 2002, s. 175). Dwa kolejne brązy to, niewystępujące nigdzie indziej w zachodniej Wielkopolsce, brzytwy. Pierwszą zaliczyć można do typu Szymocin z odznaczającą się, haczykowatą rękojeścią (ryc. 8: 3), druga zaś, ze względu na charakterystyczną rękojeść ukształtowaną w formie ucha należy do typu Gliniany (ryc. 8: 2) (Gedl, 1981, s. 31; Kaczmarek, 2002, s. 112). Oba typy brzytew grupują łącznie po trzy znaleziska, w tym cztery znalezione na terenie Dolnego Śląska oraz wspomniane dwa z Wartosławia (Kaczmarek, 2002, s. 112).

Niemal wszystkie opisane wyżej źródła archeologiczne stanowią standardowe formy przypisywane stylistyce uradzkiej, występujące na terenie zachodniej Wielkopolski i ziemi lubuskiej. Spośród nich uwagę zwraca 12 naczyń cylindrycznych z symetrycznymi uszkami, ze względu na nieprzeciętną wysokość, która oscylowała pomiędzy 12 a $19 \mathrm{~cm}$. Standardowo formy tego typu są ukształtowane do wysokości ok. 6-8 cm. Przedmiotem, który można określić mianem wyjątkowego w opisywanym zbiorze jest brązowy tutulus. Uwagę przykuwa bogate zdobienie, jak i nawiązanie stylistyczne oraz formalne do wyrobów kręgu nordyjskiego. Z terenów zachodniowielkopolskich znanych jest jeszcze pięć okazów tutulusów, lecz odróżniających się budową od wartosławskiego okazu (Kaczmarek, 2002, s. 175). 

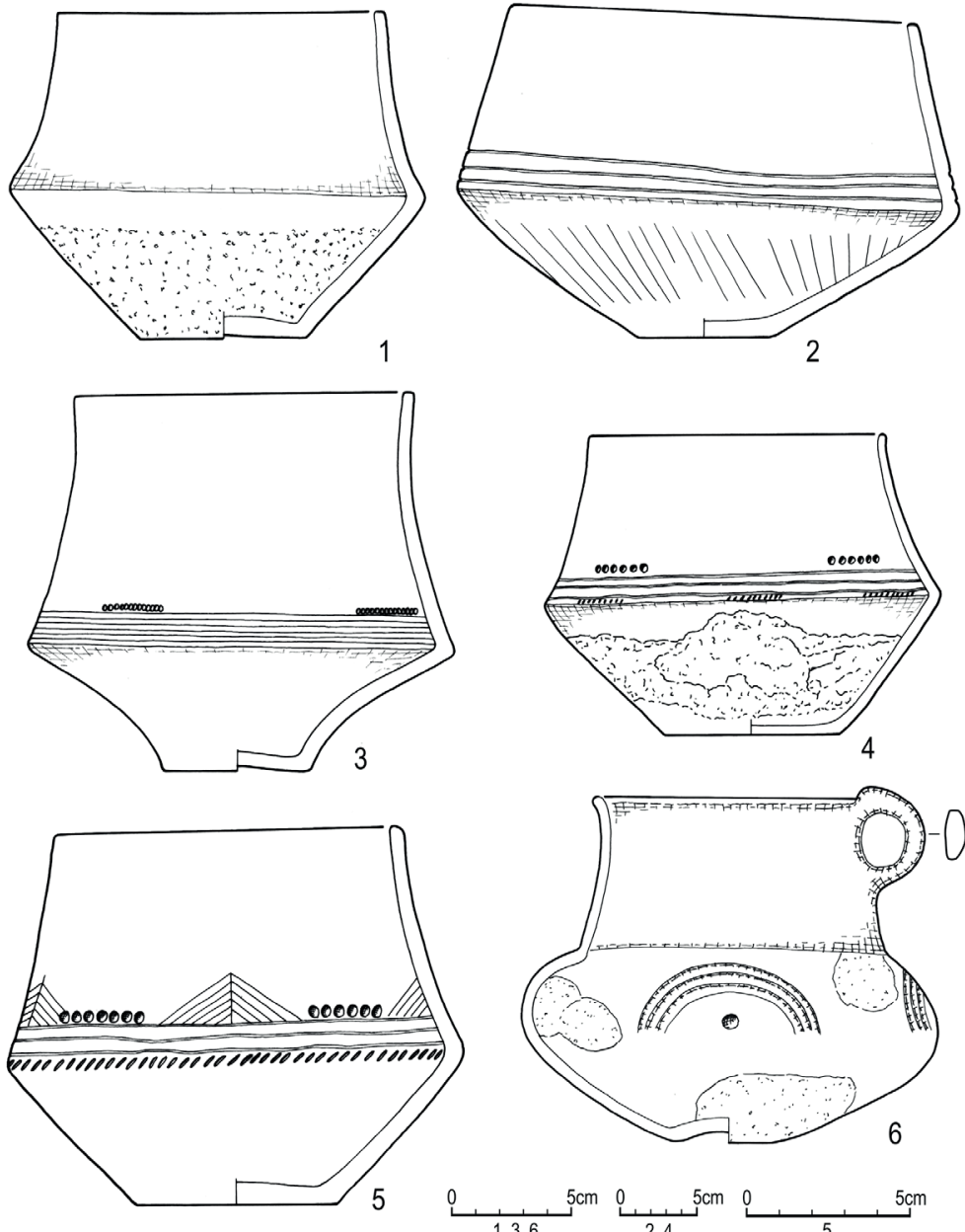



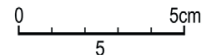

Ryc. 2. Wartosław stan. 1, pow. szamotulski. Wazy (1-5) oraz dzban (6) (rys. i oprac. komp. E. Rais-Kufel, J. Kędelska i J. Mizerka)

Fig. 2. Wartosław site 1, Szamotulski district. Vases (1-5) and a jug (6) (drawing and computer work E. Rais-Kufel, J. Kędelska and J. Mizerka) 

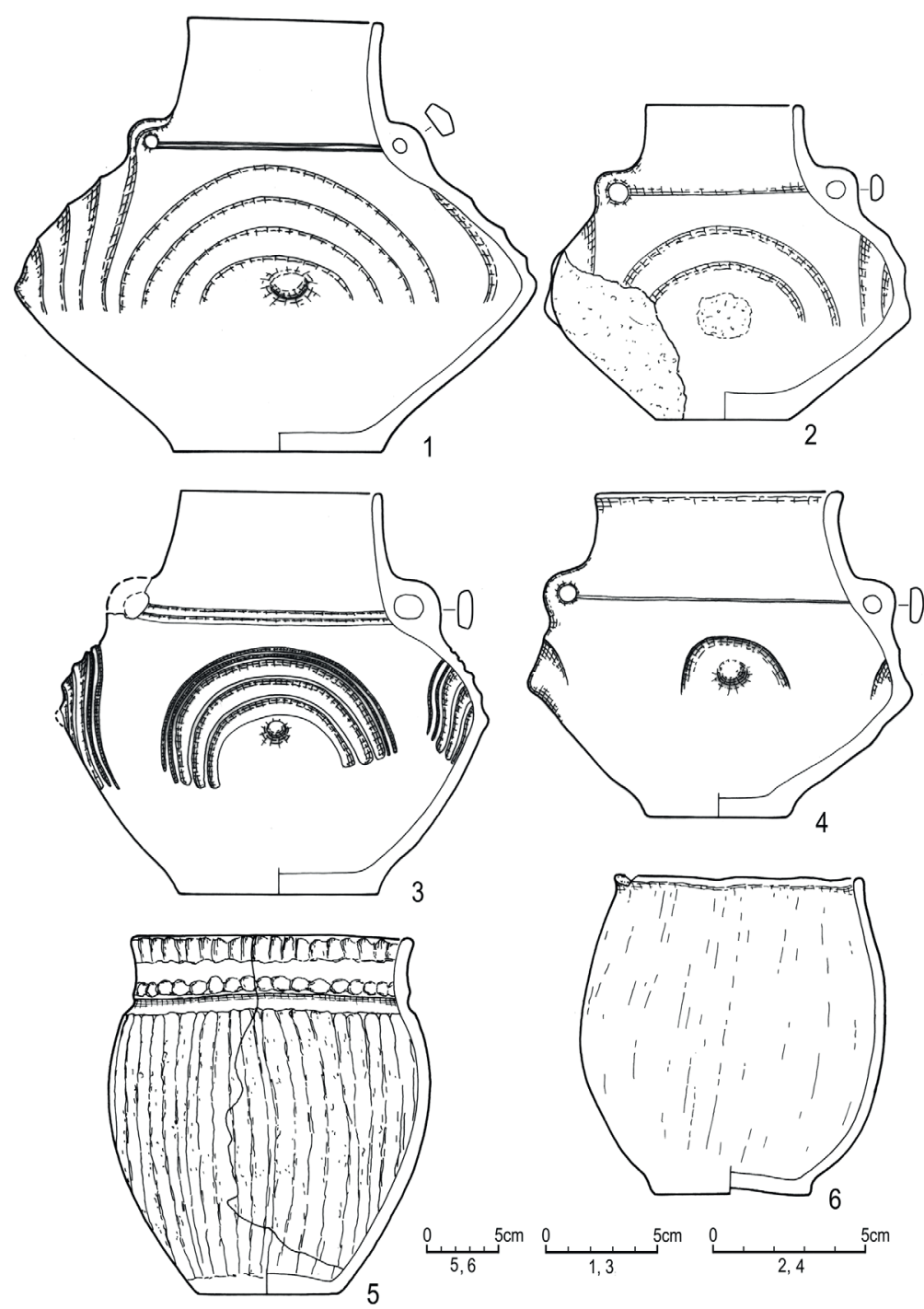

Ryc. 3. Wartosław stan. 1, pow. szamotulski. Amfory (1-4) oraz garnki (5-6) (rys. i oprac. komp. E. Rais-Kufel, J. Kędelska i J. Mizerka)

Fig. 3. Wartosław state. 1, Szamotuły district. Amphorae (1-4) and pots (5-6) (drawing and computer work E. Rais-Kufel, J. Kędelska and J. Mizerka) 

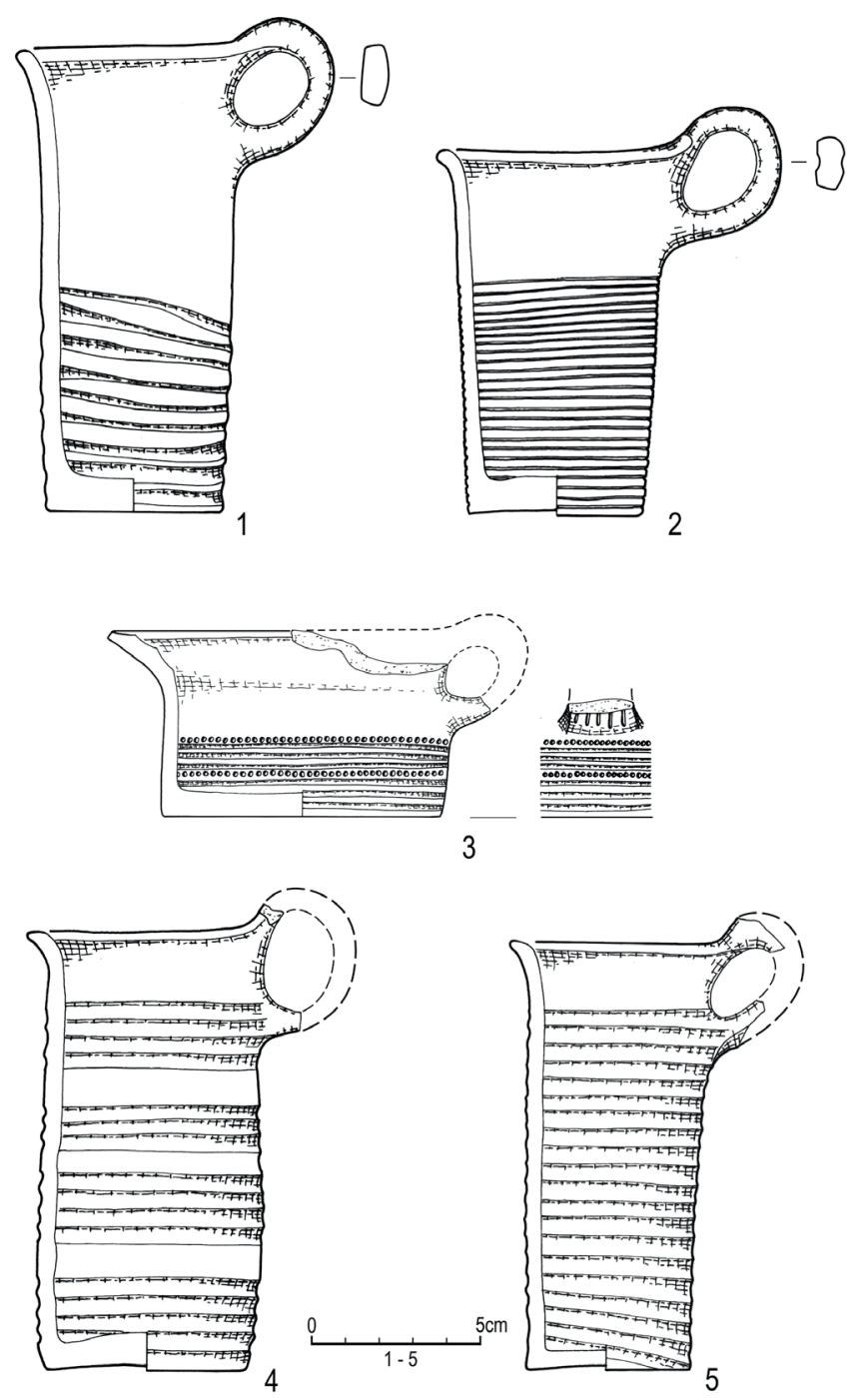

Ryc. 4. Wartosław stan. 1, pow. szamotulski. Kubki (1-5) (rys. i oprac. komp. E. Rais-Kufel, J. Kędelska i J. Mizerka)

Fig. 4. Wartosław site 1, Szamotulski district. Cups (1-5) (drawing and computer work E. Rais-Kufel, J. Kędelska and J. Mizerka) 

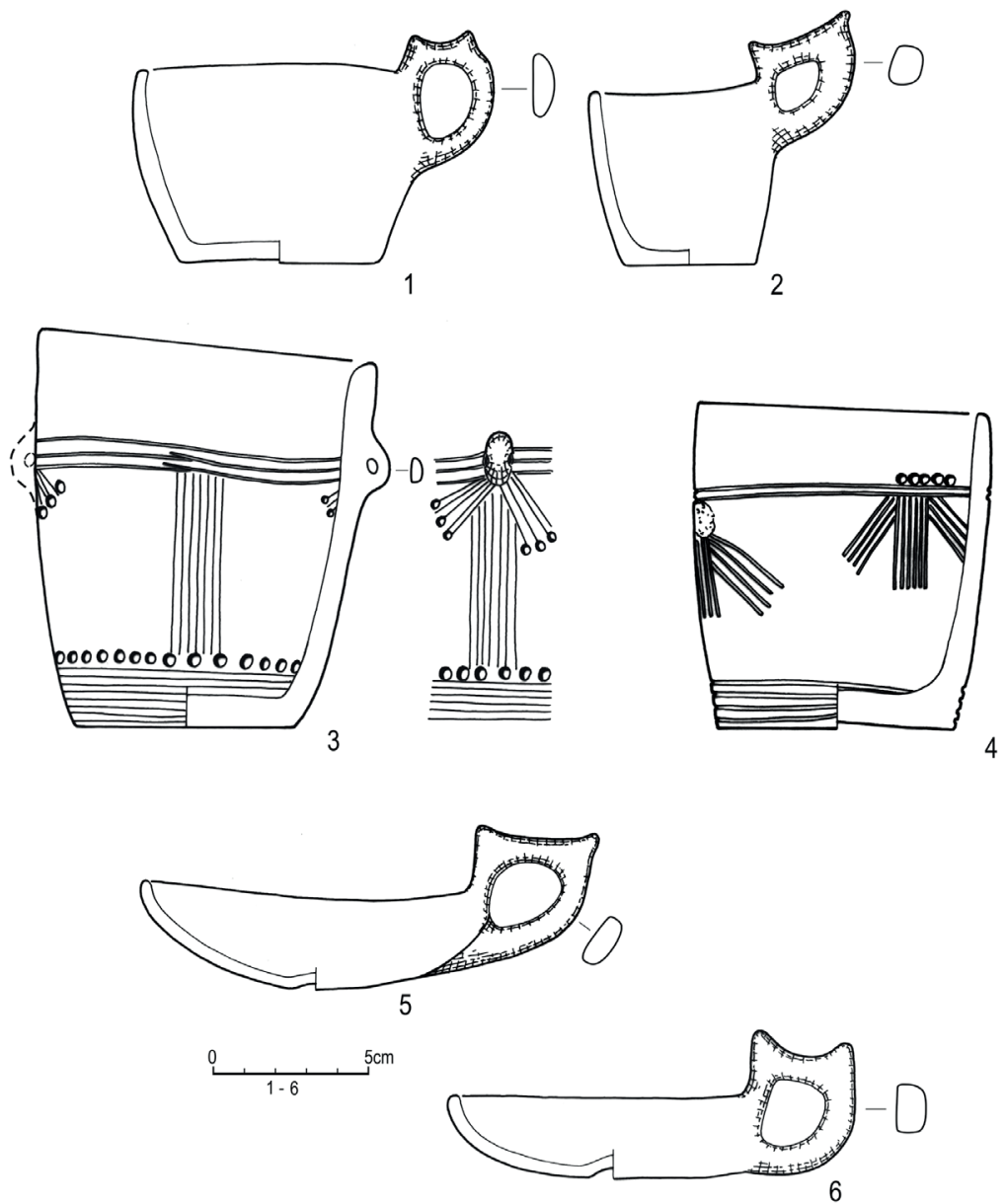

Ryc. 5. Wartosław stan. 1, pow. szamotulski. Kubki (1-4) oraz czerpaki (5-6) (rys. i oprac. komp. E. Rais-Kufel, J. Kędelska i J. Mizerka)

Fig. 5. Wartosław site 1, Szamotulski district. Cups (1-4) and buckets (5-6) (drawing and computer work E. Rais-Kufel, J. Kędelska and J. Mizerka) 

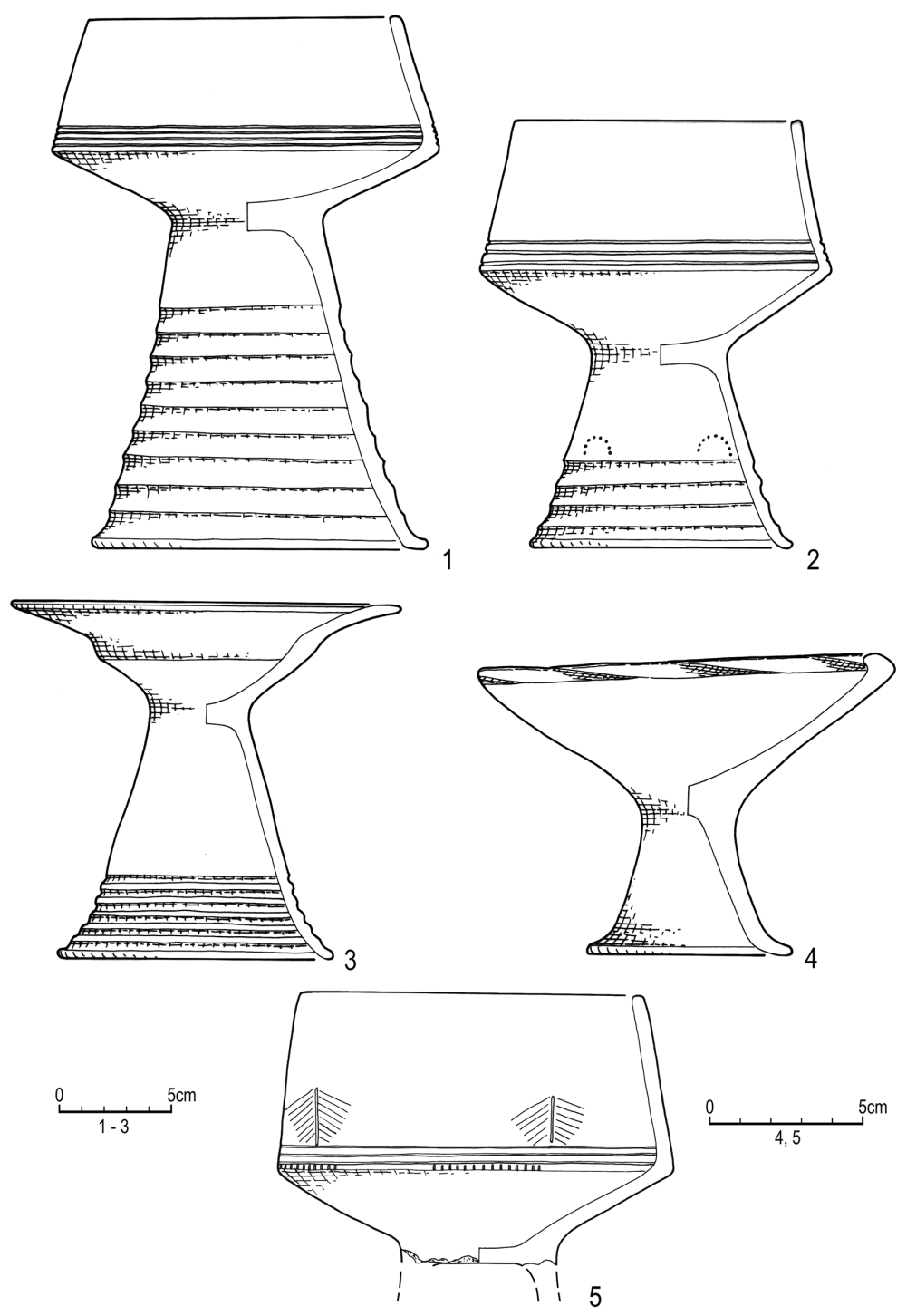

Ryc. 6. Wartosław stan. 1, pow. szamotulski. Puchary (1-5) (rys. i oprac. komp. E. Rais-Kufel, J. Kędelska i J. Mizerka)

Fig. 6. Wartosław site 1, Szamotuły district. Cups (1-5) (drawing and computer work E. Rais-Kufel, J. Kędelska and J. Mizerka) 

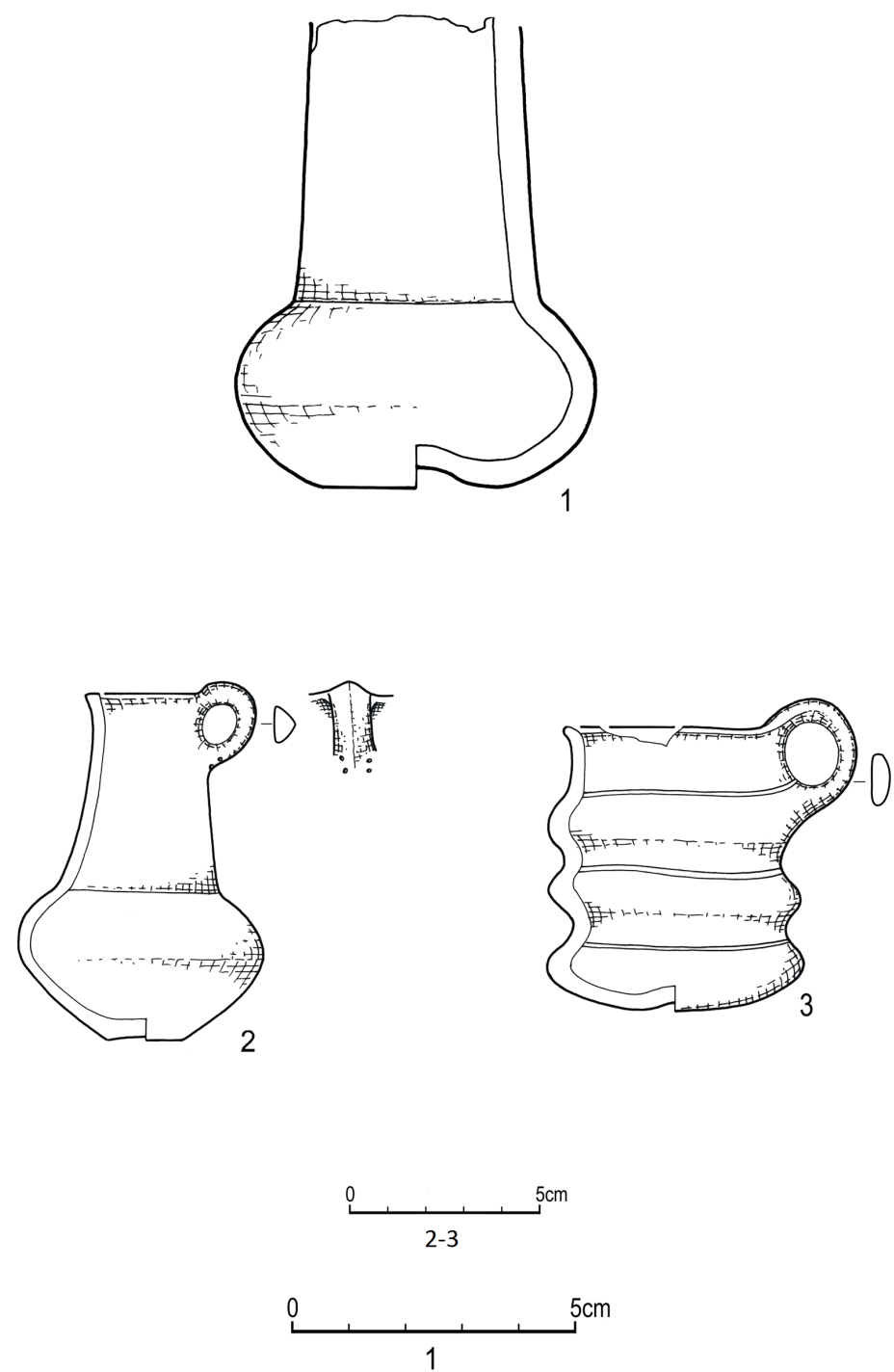

Ryc. 7. Wartosław stan. 1, pow. szamotulski. Formy specjalne (1-3) (rys. i oprac. komp. E. Rais-Kufel, J. Kędelska i J. Mizerka)

Fig. 7. Wartosław site 1, Szamotulski district. Special forms (1-3) (drawing and computer work E. RaisKufel, J. Kędelska and J. Mizerka) 

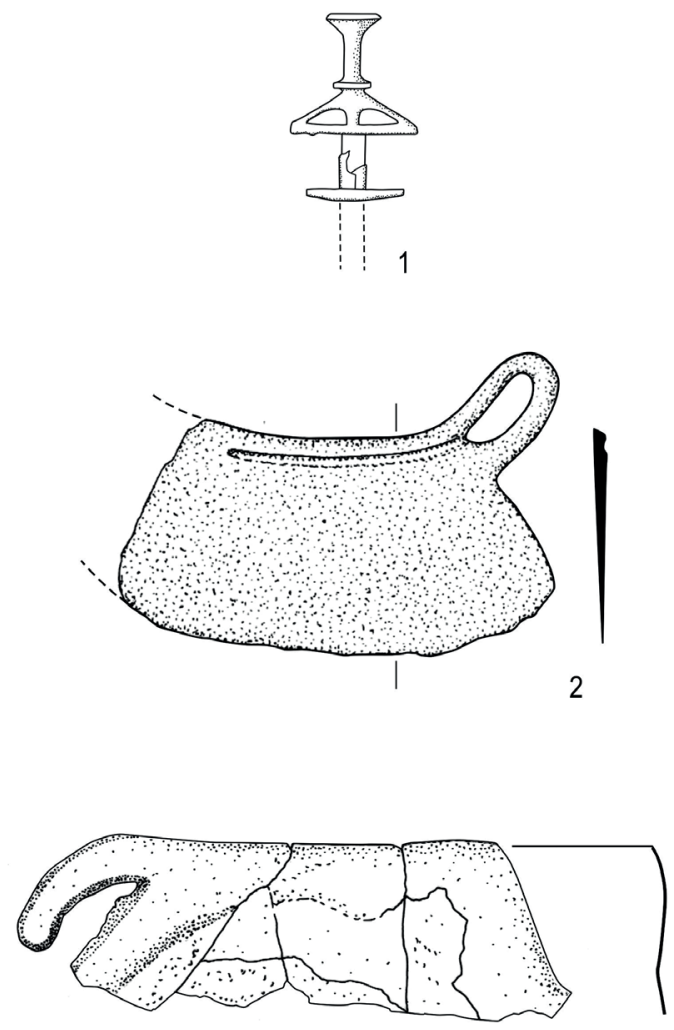

3

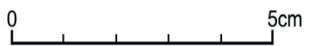

Ryc. 8. Wartosław stan. 1, pow. szamotulski. Przedmioty brązowe: tutulus (1), brzytwy (2-3) (rys. i oprac. komp. E. Rais-Kufel, J. Kędelska i J. Mizerka)

Fig. 8. Wartosław site 1, Szamotulski district. Brown items: tutulus (1), razors (2-3) (drawing and computer work E. Rais-Kufel, J. Kędelska and J. Mizerka) 


\section{PODSUMOWANIE}

W literaturze przedmiotu przyjęto, że stylistyka uradzka jest odzwierciedleniem wewnętrznego zróżnicowania łużyckich pól popielnicowych oraz ich postępującej regionalizacji. Zauważalna jednolitość stylistyczna manifestująca się w materiale ceramicznym dotyczy terenów wschodniej Brandenburgii, ziemi lubuskiej oraz zachodniej Wielkopolski, które włączono w obręb grupy zachodniowielkopolskiej (Marcinkian, 1974, s. 52-53; 1986, s. 110-111; 2010a; 2010b; Kaczmarek, 2002, s. 71-72). W młodszym okresie epoki brązu widoczna jest ogólna tendencja do kształtowania ceramiki o ostrych załomach (Gedl, 1980b, s. 84). Rejestrowana jest ona na terenach wschodniowielkopolskich, a przykład stanowią naczynia z cmentarzysk w Sierszewie (Zeylandowa, 1965, s. 83, ryc. 13, s. 86, ryc. 29: 5, 7), Mariankach (Szamałek, 2009, s. 113, ryc. 55: 1, 2, 5) czy Kaliszanach (Szamałek, 2009, s. 115, ryc. 57). Również na obszarze Śląska występuje trend kształtowania silnych załomów naczyń, a w zakresie zdobnictwa występują podobne wątki w postaci linii rytych czy jodełki (Gedl, 1980a, s. 94-97; Gediga, 1982, tabl. I; 1980a, s. 94-99; Gediga, 1967, s. 184, 185; 1982, tabl. 1). Ceramika tego typu występuje m.in. na cmentarzyskach w Kietrzu (faza Kietrz IIIIVa), Przyborowie (Marcinkian, 1972, tabl. XI: 7,8, XXI: 3; XXXIX: 9) czy Gołaszynie (Marcinkian, 1974, s. 62, tabl. VII: 2). O ścisłych kontaktach utrzymywanych pomiędzy Śląskiem a zachodnią Wielkopolską świadczą znajdowane przedmioty metalowe wykonane w podobnych typach (Kaczmarek, 2001, s. 89). W zakresie metalurgii to właśnie ośrodki śląskie dostarczały gotowych produktów, jak i inspiracji do ich wytwarzania. W przypadku materiałów z Wartosławia potwierdzałyby ten fakt dwie brzytwy o śląskich nawiązaniach.

Badacze epoki brązu są zgodni, że obecnie problem stanowi definicja oraz nazywanie całego zjawiska „kulturą łużycką” (Dąbrowski, 1980; Gediga, 1983; 2010, s. 212; 2011, 83-116;). Zwracano przy tym uwagę na wytworzony w literaturze przedmiotu konglomerat, jaki tworzy owa „kultura łużycka” i jest nieprzerwanie używany do opisu wycinka czasu obejmującego tysiąc lat (Gediga, 2007, s. 124; 2011; 2018). Ponadto stosowany do dzisiaj podział typologiczno-klasyfikacyjny źródeł archeologicznych, stworzony przez J. Kostrzewskiego (1965, s. 192-219), prowadzi do zauważania odmienności pomiędzy poszczególnymi regionami. Wydzielane na tej podstawie grupy miały porządkować różnice wynikające z chronologii oraz lokalnej specyfiki. Stosunkowo niedawno ukształtowało się zgoła przeciwne podejście, u którego podstaw leży dostrzeganie elementów wspólnych i łączących poszczególne regiony. Przykład stanowić może sytuacja kulturowa Śląska u progu wczesnej epoki żelaza. Najnowsze odkrycia dokonane w Domasławiu/Chrzanowie (Gediga, Józefowska, 2019), lecz również na kilku innych stanowiskach ${ }^{4}$ pozwoliły na postawienie tezy, że opisywany obszar stanowi regionalną prowincję kultury halsztackiej, inaczej nazywaną strefą wpływu kultury halsztackiej. Skłania to do

\footnotetext{
4 Stanowiska w Kietrzu, pow. głubczycki; Gorszewicach, pow. szamotulski; Łazach, pow. wołowski; Milejowicach, pow. wrocławski (Gediga, 2010, s. 190-191).
} 
refleksji, jak należy postrzegać i definiować „kulturę łużycką” na Śląsku, a także jak w tym kontekście kształtuje się sytuacja na obszarach ościennych (Gediga, 2011, s. 87). Próbując zastosować podobny model i spojrzeć kompleksowo na przedstawioną problematykę dotyczącą studiów nad ceramiką, wydaje się, że mimo pewnych odmienności zauważalne są ogólne tendencje stylistyczne. Dowodem na to jest istnienie w ceramice naczyniowej stylu guzowego w III EB, ostroprofilowanego w IV EB oraz późnobrązowego w V EB na wymienianych wyżej terenach. Oznacza to, że stylistyka uradzka stanowi o pewnego rodzaju regionalizacji terenu, lecz nie zaświadcza o istnieniu zamkniętej, terytorialnej grupy, wyraźnie odróżniającej się od terenów ościennych. Wpisuje się w trend tworzenia naczyń ostroprofilowanych, które pojawiały się w zachodniej i wschodniej Wielkopolsce, na Śląsku oraz ziemi lubuskiej. Obserwacje przemian kulturowych na Śląsku, które pozwoliły na dostrzeżenie i weryfikację obrazu kulturowego tego obszaru, skłaniają do zmiany postrzegania pewnych zjawisk (Gediga, 1982, s. 51; 2010). Styl uradzki stanowi interesujący przykład, który można traktować jako pewnego rodzaju poligon w ustalaniu nowych interpretacji. Zasadność wydzielania tej stylistyki odznaczającej się konkretnym zestawem naczyń ceramicznych wydaje się być niepodważalna. Należy jednak mieć na uwadze nowe spojrzenie na łużyckie pola popielnicowe, które przedkłada widzenie procesów i scalanie obrazu kulturowego danych obszarów nad charakteryzowanie i wydzielanie grup regionalnych.

\section{BIBLIOGRAFIA}

Bukowski, Z.

1998 Pomorze w epoce brązu w świetle dalekosiężnych kontaktów wymiennych. Gdańsk: Gdańskie Towarzystwo Naukowe.

Durczewski, D.

1986 Cmentarzysko ludności kultury łużyckiej z IV-V okresu epoki brązu w Kaliszanach, woj. Pilskie. Fontes Archeaeologici Posnanienses, 35, 41-98.

Gediga, B.

1967 Plemiona kultury łużyckiej w epoce brązu na Śląsku środkowym. Wrocław - Warszawa Kraków: Zakład Narodowy im. Ossolińskich.

1982 Zagadnienia periodyzacji okresu rozwoju kultury łużyckiej w świetle kontaktów z Południem. W: M. Gedl (red.), Poludniowa strefa kultury tużyckiej i powiazania tej kultury z południem (s. 49-59). Kraków - Przemyśl: Instytut Archeologii Uniwersytetu Jagiellońskiego.

2007 Problemy obrazu kultury wczesnej epoki żelaza na Śląsku w świetle nowych badań terenowych. Ślaskie Sprawozdania Archeologiczne, 49, 123-146.

2010 Śląsk - regionalna prowincja kultury halsztackiej. W: B. Gediga, W. Piotrowski (red.), Rola głównych centrów kulturowych w ksztaltowaniu oblicza kulturowego Europy Środkowej we wczesnych okresach epoki żelaza (s. 187-218). Biskupin - Wrocław: Muzeum Archeologiczne w Biskupinie.

2011 Neue Forschungen zu den früheisenzeitlichen Kulturen in Südwestpolen. Acta Archaeologica Carpathica, 46, 83-116. 
2018 Bemerkungen über den begriff „Lausitzer kultur” heute. W: L. Benediková. M. Horňák (red.), Sídla, artefakty a čas... Zbornik štúdii o dobe bronzovej a dobe halštatskej $k 75$. narodeninám Ladislava Veliačika (s. 105-111). Nitra - Vrutky: Archeologický ústav SAV.

Gediga, B. Józefowska, A.

2019 Przemiany obrzadku grzebalnego w epoce brąu i wczesnej epoce żelaza w świetle analizy źródet w Domastawiu, pow. wroctawski i nekropolii bliskiego rejonu (problemy zmian społeczno-kulturowych). Wrocław: Instytut Archeologii i Etnologii PAN.

Gedl, M.

1975 Kultura łużycka. Kraków: Wydawnictwo Ossolińskich.

1980a Studia nad periodyzacją kultury łużyckiej w południowej części Śląska. Archeologia Polski, 25, 79-129.

1980b Zróżnicowanie kulturowe w strefie zaliczanej do „kultury łużyckiej”. W: M. Gedl (red.), Zróżnicowanie wewnętrzne kultury tużyckiej (s. 78-94). Kraków: Instytut Archeologii Uniwersytetu Jagiellońskiego.

Götze, A.

1897

Die Vorgeschichte der Neumark. Würzburg: A. Stuber Verlag.

1924 Aurither Typus. W: M. Ebert (red.), Reallexikon der Vorgeschichte, t. 1 (s. 278-279). Berlin.

Kaczmarek, M.

2001 Niektóre aspekty badań nad kulturą łużycką młodszej epoki brązu w zachodniej Wielkopolsce. Sprawozdania Archeologiczne, 53, 85-98.

2002 Zachodniowielkopolskie społeczności kultury tużyckiej w epoce brąu. Poznań: Wydawnictwo Naukowe Uniwersytetu Adama Mickiewicza.

2005 Epoka brązu i wczesna epoka żelaza na ziemi obornicko-rogozińskiej. W: T. Skorupka (red.), Archeologia powiatu obornickiego. Oborniki-Rogoźno-Ryczywót (s. 127-235). Poznań: Wydawnictwo Muzeum Archeologicznego w Poznaniu.

2008 Remarks on the Urad type pottery style in Lubusz Land and western Wielkopolska during Late Bronze Age. W: A. Błażejewski (red.), Labor et Patientia. Studia archaeologica Stanislao Pazda (s. 19-35). Wrocław: Wydawnictwo Instytutu Archeologii Uniwersytetu Wrocławskiego.

2013 Uwagi o stanie i potrzebach badań nad cmentarzyskami ludności łużyckich pól popielnicowych na Nizinie Wielkopolsko-Kujawskiej. W: J. Kolenda, A. Mierzwiński, S. Moździoch, L. Żygadło (red.), Z badań nad kultura społeczeństw pradziejowych i wczesnośredniowiecznych. Księga Jubileuszowa dedykowana Profesorowi Bogusławowi Gedidze w osiemdziesiąta rocznicę urodzin przez przyjaciót, kolegów i uczniów (s. 237-249). Wrocław: Instytut Archeologii i Etnologii Polskiej Akademii Nauk.

Kostrzewski, J.

1955 Wielkopolska w pradziejach, wyd. 3. Warszawa - Wrocław: Zakład im. Ossolińskich.

Kostrzewski, J., Chmielewski, W., Jażdżewski, K.

1965 Pradzieje Polski. Wrocław - Warszawa - Kraków: Zakład im. Ossolińskich. Krzyszowski, A.

2009 Sprawozdanie z badań wykopaliskowych na stanowisku archeologicznym $w$ Wartostawiu, stan. 1 (ark. AZP 46-21, nr 33), gm. Wronki, w woj. wielkopolskim ( $w$ obrębie dziatki $n r$ ew. 80432/2) [maszynopis w archiwum WUOZ w Poznaniu].

2019 Zagadnienia wprowadzające. W: A. Krzyszowski (red.), Nekropola z późnej epoki brąu Wartostaw-Biezdrowo-Zakrzewo (s. 13-21). Poznań: Wydawnictwo Muzeum Archeologicznego w Poznaniu.

2019 Grób odlewnika-metalurga (obiekt nr 198) z badań w 2009 roku. W: A. Krzyszowski (red.), Nekropola z późnej epoki brązu Wartosław-Biezdrowo-Zakrzewo (s. 73-87). Poznań: Wydawnictwo Muzeum Archeologicznego w Poznaniu. 
Łopata, J.

1964 Cmentarzysko ludności kultury łużyckiej z IV-V okresu epoki brązu w Wartosławiu pow.

Szamotuły. Fontes Archaeologici Posnanienses, 15, 12-76.

Machajewski, H.

2005 Sprawozdanie z archeologicznych badań przeprowadzonych na stanowisku 1 w Wartosta-

Malinowski, T. wiu, gmina Wronki [maszynopis w archiwum WUOZ w Poznaniu].

1961 Katalog cmentarzysk ludności kultury tużyckiej w Polsce, t. 1. Poznań: Polska Akademia Nauk.

Marcinkian, A.

1974 Stan badań nad kulturą łużycką epoki brązu w północnej części Dolnego Śląska. Zielonogórskie Zeszyty Muzealne, 4, 41-65.

1986 Z badań nad epoką brązu i wczesną epoką żelaza na Ziemi Lubuskiej. Rocznik Lubuski, $14,103-118$.

2010a Ziemia lubuska w dobie cywilizacji hużyckiej, cz. 1 - katalogowa. Zielona Góra: Totem.

2010b Ziemia lubuska w dobie cywilizacji łużyckiej, cz. 2 - analityczna. Zielona Góra: Totem.

Mizerka, J.

2016 Wartosław-późnobrąowe cmentarzysko z zachodniej Wielkopolski. Wyniki badań ratowniczych z 2009 roku [maszynopis pracy magisterskiej, Uniwersytet im. Adama Mickiewicza w Poznaniu].

2019 Wyniki badań archeologicznych z 2009 roku. W: A. Krzyszowski (red.), Nekropola z późnej epoki brazu Wartosław-Biezdrowo-Zakrzewo (s. 45-73). Poznań: Wydawnictwo Muzeum Archeologicznego w Poznaniu.

Mizerka, J., Krzyszowski, A.

2019 XIX-wieczne materiały z cmentarzyska z Wartosławia-Biezdrowa-Zakrzewa w zbiorach MAP. W: A. Krzyszowski (red.), Nekropola z późnej epoki brąu Wartosław Biezdrowo - Zakrzewo (s. 29-45). Poznań: Wydawnictwo Muzeum Archeologicznego w Poznaniu.

Schneider, F.

1958 Die Keramik des Aurither Stils westlich der Oder. W: Schneider F. (red.), Studien zur Lausitzer Kultur (s. 5-70). Leipzig: Johann Ambrosius Barth.

Szamałek, K.

2009 Procesy integracji kulturowej w młodszej epoce brąu i początkach epoki żelaza na Pojezierzu Wielkopolskim. Poznań: Instytut Archeologii i Etnologii Polskiej Akademii Nauk.

Virchow, R.

1880 Der Spreewald und die Lausitz. Zeitschrift filr Ethnologie, 12, 222-236.

Voss, A.

1903 Keramische Stilarten der Provinz Brandenburg und benachbarter Gebiete. Zeitschrift filr Ethnologie, 35, 163-212.

Voss, A., Stimming, G.

1887 Vorgeschichtlicher Alterthilmer aus der Mark Brandenburg. Brandenburg - Berlin: Hardcover.

Zeylandowa, M.

1965 Cmentarzysko kultury łużyckiej w Sierszewie, pow. Jarocin. Fontes Archaeologici Posnanienses, 16, 79-103. 


\section{CONTRIBUTION TO THE RESEARCH ON THE URAD STYLE \\ IN THE WESTERN GREATER POLAND, BASED ON THE EXAMPLE OF MATERIALS FROM THE CEMETERY IN WARTOSŁAAW, SZAMOTULSKI DISTRICT}

\section{Sum mary}

This article addresses the issue of Urad stylistics, presenting the history of research, the crystallization of the current definition of this phenomenon and the possibilities of its interpretation. The background to the conclusions are materials from the necropolises in Wartosław, which can be combined with IV EB. Although the research on Urad stylistics, which is one of the distinguished styles in the pottery produced by the population of Lusatian urnfields, dates back to the end of the 19th century, and in western Greater Poland materials this pottery was often identified, it was not clearly stated what processes should be associated with its appearance in a rather limited area covering western Greater Poland, the Lubusz region and Brandenburg. It will be a truism to say that new data can be provided by in-depth studies on materials obtained from cemeteries and settlements of the Lusatian urnfields. These do not have to be based only on the currently obtained materials, but also on older ones, which can be re-interpreted. Materials from the cemetery in Wartosław were subjected to such a reanalysis, in order to draw attention to the so far inexhaustible problems of Urad stylistics in western Greater Poland.

Simultaneously with the introduction of the term "Lusatian type" into circulation, archaeological materials obtained from the eponymous cemetery in Urad became the basis for the creation and introduction into circulation of the concept of the Urad style by A. Voß. The first attempt to characterize the above-mentioned phenomenon was made by A. Götze in 1897. This sketch was extended a few years later by the aforementioned researchers, who also determined the scope of a separate Urad group. On the other hand, in Polish literature, the term Uradzka group began to be used indiscriminately as it was identical with the western Greater Poland region and encompassed all the younger and late brown ceramics (IV-V EB), which was to fill the gap between the characteristic knobble ceramics, developing at the beginning of the functioning of the Lusatian urnfields, and the diagnostic Hallstatt ceramics, crowning the development of the described cultural unit. He significantly limited and redefined the concept of the Urad style by M. Gedl, who in the proposed term included ceramics characterized by sharp profiling, appearing in eastern Brandenburg, in the Lubuskie region and in western Greater Poland in IV EB. This approach was introduced and is now used in the Polish literature on the subject.

Currently, Urad ceramics is understood as the so-called information package on its morphology and ornamentation. The most important and distinctive feature is the sharp profiling of the vessels, resulting from the significant simplification of the vessel tectonics and the shaping of sharp bends. The characteristic biconical bellies have vessels of various types: vases, amphoras and jugs. Their surfaces are often covered with so-called residual knobble ornament, referring to the previous developmental stage, i.e., the knobble style. There are also conical bowls, mortar-shaped mugs and tall cylindrical mugs, usually accompanied by simplified ornamental motifs based on engraved and imprinted elements. Herringbone is the distinctive ornamental motif for the period in question. Urad cups are particularly diagnostic, as evidenced by the fact that at the beginning of the Urad-style research they formed the basis for determining its territorial range. They are characterized by tall, hollow legs, often decorated with circumferential cannells, on which are placed vase-shaped or bowl-shaped forms.

It might seem that such a characteristic set, which characterizes pottery, is not difficult to identify and clearly distinguish. When it comes to individual dishes, this is indeed the case. However, inventories containing a greater number of more diverse forms pose problems. We note a continuous 
lack of transitional syndromes in which knobble and Urad ceramics coexist, marking the initial stage of development. On the other hand, with regard to the disappearance of its use, many inventories were discovered containing fine and late-brown materials, which are a kind of transition to "clean" sets with late-brown ceramics. Due to this fact, it is suggested that a separate, transitional phase should be distinguished, which in fact manifests itself in the frequent inability to clearly define the style and chronology in material studies, closing within IV-V EB.

Cemetery of the population of Lusatian urnfields in Wartosław, site 1, also known as Wartosław-Biezdrowo-Zakrzewo, is located in the north-western part of Greater Poland. The site has been known since the end of the 19th century, when amateur digging of graves began there. The archaeological materials obtained in this way, mainly vessels, but also metal and stone objects, were part of the private collection of the counts Węsierski-Kwilecki, later donated to the Archaeological Museum in Poznań. The first methodical excavation research in the 1960s was carried out by Janusz Łopata, who identified 121 tombs in the central part of the cemetery. However, most likely the north-western part of the necropolis was examined in 2009 by the team of the Archaeological Museum in Poznań, discovering 82 graves. In terms of quantity, the largest collection are materials obtained in the 19th century, as there are over 900 forms of vessels and 122 other clay, metal and stone monuments. The research of J. Łopata includes 423 completely preserved vessels and about 30 other items. Grubbing and forest plowing, as well as the increased activity of illegal searches with the use of metal detectors, led to a significant destruction of objects and grave inventories, which was recorded during the research in 2009. Over 560 vessel forms, 13 bronze objects and 36 stone objects were distinguished. It should be noted that the percentage of the vessels preserved in their entirety was incomparably lower than during the previously conducted research in the cemetery. Undoubtedly, however, finds having a context, and at the same time creating a compact inventory, are more important for the discussed issues than the excellent condition of the collection of monuments.

The 19th century collection included vessel forms whose morphological features allowed them to be associated with the Urad style. Probably in some cases, the inspection of the entire grave inventory would determine the recognition of the transitional character between the Urad style and the late-brown style, as was the case with the funerary complexes from 2009. Nevertheless, the charming style, due to the tectonics of the vessels and ornamentation, was assigned 268 vessels. Among them were large-size forms (such as vases, amphorae, jugs), smaller forms (such as cups, scoops, goblets) and extremely rare special forms. There were only a few extra-thermic products that could be attributed to this chronological group - only three brown items. Among them there was a richly decorated tutulus with a spike coming out of the upper shield, the structure and ornamentation of which indicate belonging to the type with a mushroom head according to the division of E. Sprockhoff, characteristic of the southern zone of the Norse culture. The second item was a Szymocin razor with a hooked handle. The third was also a razor, the shape of which indicates the Clay type. It had a characteristic handle shaped as ear-type.

The archaeological material obtained from 82 funerary complexes discovered during the excavations in 2009 allowed for a chronological analysis in 77 cases. The typology of vessel forms and their ornamentation were adopted as the basis of the chronology, while the metal objects found in the graves played a secondary role, which in the Lusatian materials of urnfields do not constitute basic chronological indicators. The elements of the funeral rite, such as the types of burials or the construction of graves, do not differ chronologically either. Five funerary complexes were connected with the described development stage.

The arrangement of graves in the cemetery was considered taking into account the chronological aspect. The coexistence of all the graves, dated IV, V and IV-V EB, was observed in one part of the cemetery, which was also noticed by J. Łopata during his excavations. However, a question arises whether we are dealing with a smooth transition between the new and late brown ceramics, as 
evidenced by the joint location of the graves, or whether there has not yet been a "clean" part of the cemetery with only the horizon of Urad ceramics. The first thesis is supported by the fact that most of the cemeteries of the Lusatian urnfields have a similar situation. On the other hand, the advantage of the latter is that there are still no large cemeteries that have been comprehensively and systematically examined, such as the one in Wartosław. Until that happens, doubts about its functioning will still be a matter of guesswork.

The concentration of the sites in the areas of western Greater Poland and the Lubusz region made it possible to divide them into settlement groups. The described cemetery in Wartosław belongs to the Poznań-Szamotuły grouping, which is, among six others, the most dense cluster, which results both from the preferences of the then communities in the selection of settlement sites, as well as the intensification of archaeological research in this area. The maps created on this basis make it possible to trace the settlement density with regard to the chronological aspect. The appearance of the Lusatian urnfields culture community in large areas of Greater Poland in the 4th EB is very clear, where this unit previously appeared in points, and then its intensive development in the next period. The western direction of the influx of cultural information is beyond doubt. The stylistic uniformity is noticeable, which is manifested in the ceramic material found in eastern Brandenburg, in the Lubusz region and in western Greater Poland. In the light of the above-mentioned theses, the key to the considerations is the willingness to understand what is meant by the term "uradzka style". Is it one of the components of the cultural information package that we should read as an element that defines a distinct population group? It can be proved by the intensive development of settlement, with the simultaneous lack of temporary inventories. Also, a strong unification of material culture, which included the aforementioned areas, could indicate the functioning of a separate community. Or maybe it is only a stage in the development of ceramics in the Lusatian urnfields? Although it is a territorially limited phenomenon, it is part of the tendency to form groups within the described cultural unit. Therefore, it seems that at the present stage of research, it can be concluded that the unification that we register in the described areas results from its belonging to a wide range of Lusatian urnfields, with simultaneous regionalization, which is manifested in the Urad style. 